\title{
Treatment of Acne in Pregnancy
}

\author{
Anna L. Chien, MD, Ji Qi, BA, Barbara Rainer, MD, Dana L. Sachs, MD, \\ and Yolanda R. Helfrich, $M D$
}

Acne vulgaris is a common disease of the pilosebaceous unit and affects adolescents and adults. Because high-quality guidelines regarding treatment of acne in pregnancy are scarce, management of this condition can be challenging. We describe the safety profile of common therapies and outline approaches based on available evidence. Topical azelaic acid or benzoyl peroxide can be recommended as baseline therapy. A combination of topical erythromycin or clindamycin with benzoyl peroxide is recommended for inflammatory acne. Oral erythromycin or cephalexin is generally considered safe for moderate to severe inflammatory acne when used for a few weeks. A short course of oral prednisolone may be useful for treating fulminant nodular cystic acne after the first trimester. In general, topical and oral antibiotics should not be used as monotherapy, but combined with topical benzoyl peroxide to decrease bacterial resistance. Oral retinoids are teratogenic and absolutely contraindicated for women who are pregnant or considering pregnancy. Although some complementary therapies including micronutrients and nonpharmacologic treatments seem to be well tolerated, limited data exist regarding their safety and efficacy, and they are not currently recommended during pregnancy. The risk-to-benefit ratio, efficacy, acceptability, and costs are considerations when choosing a treatment for acne in pregnancy. (J Am Board Fam Med 2016;29:254-262.)

Keywords: Acne, Dermatology, Maternal Health, Pregnancy

Acne vulgaris is a chronic inflammatory disorder of the pilosebaceous unit and is characterized by noninflammatory (comedones) and inflammatory lesions (papules, pustules, and nodules) that can cause scarring and psychological distress. In women who are planning pregnancy or who are pregnant, this condition can be particularly bothersome given the physiologic changes as well as the unpredictable nature of acne during this time. ${ }^{1}$ Acne often improves during the first trimester but may worsen during the third trimester as a result of increased maternal androgen concentrations and the resultant effects on sebum production. ${ }^{2}$ In addition to hormonal changes, pregnancy-associated immuno-

This article was externally peer reviewed.

Submitted 20 May 2015; revised 2 September 2015; accepted 9 September 2015.

From the Department of Dermatology, Johns Hopkins University, Baltimore, MD (ALC, JQ, BR); and the Department of Dermatology, University of Michigan, Ann Arbor (DLS, YRH).

Funding: none.

Conflict of interest: none declared.

Corresponding author: Anna L. Chien, MD, Department of Dermatology, Johns Hopkins University, 601 N. Caroline St, Suite 8033, Baltimore, MD 21287 (E-mail: achien3@ jhmi.edu). logic factors may also contribute. ${ }^{3}$ Inflammatory lesions tend to be more common than noninflammatory lesions, often with involvement extended to the trunk. Patients with a history of acne are more prone to developing acne during pregnancy. ${ }^{4}$

Management of acne in pregnant patients can be challenging because many widely used and effective therapeutic options are contraindicated or not recommended. Thus it is important for prescribers to be familiar with treatment restrictions and the US Food and Drug Administration (FDA) pregnancy drug classifications for the commonly used acne medications (Table 1). Because of inherent ethical issues surrounding clinical trials during pregnancy, pharmacokinetic and pharmacodynamic data assessing drug safety during pregnancy are limited, and randomized controlled trials of acne medications do not exist. Thus most treatment recommendations are based on observational and animal studies. Here we review the safety and efficacy data of common acne medications and outline a practical approach for managing acne during pregnancy based on the latest available data (Table 2). Armed with this information, clinicians can develop a safe and effective acne regimen for this unique patient population. 
Table 1. Food and Drug Administration Pregnancy Risk Categories

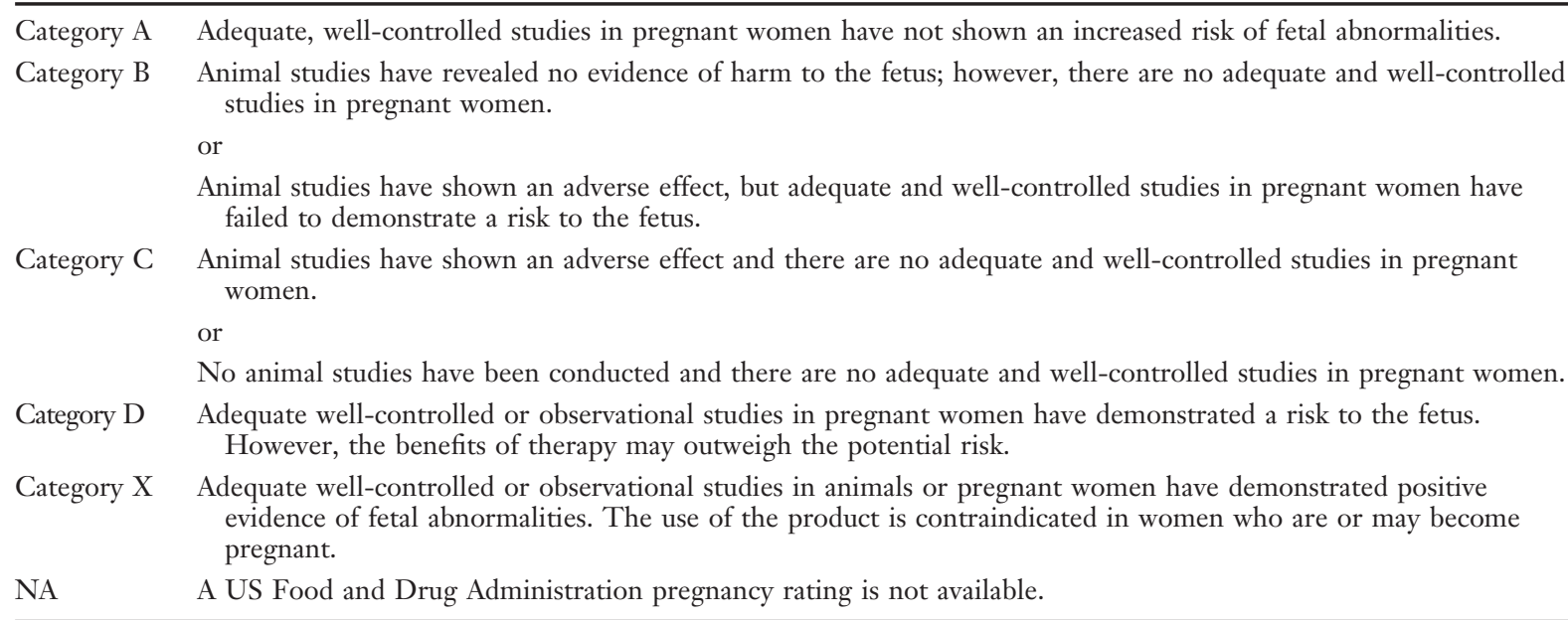

\section{Literature Search and Data Sources}

For this review, PubMed was searched in Clinical Queries using the following key terms: acne, pregnancy, azelaic acid, benzoyl peroxide, salicylic acid, erythromycin, clindamycin, azitbromycin, amoxicillin, retinoids, isotretinoin, topical, systemic, antibiotics, trimethoprim-sulfamethoxazole, teratogenicity, corticosteroids, safety, zinc, glycolic acid, aminole-

Table 2. Treatment Algorithm for Acne in Pregnancy

\begin{tabular}{|c|c|c|c|}
\hline Type of Acne & Treatment & FDA Pregnancy Drug Class & Evidence Rating \\
\hline \multicolumn{4}{|l|}{ Noninflammatory } \\
\hline Comedonal & Azelaic acid & $\mathrm{B}$ & Likely to be beneficial \\
\hline \multicolumn{4}{|l|}{ Inflammatory } \\
\hline \multirow[t]{5}{*}{ Mild to moderate } & $\begin{array}{l}\text { Azelaic acid } \\
\quad+\end{array}$ & B & Likely to be beneficial \\
\hline & $\begin{array}{l}\text { Benzoyl peroxide } \\
\text { or }\end{array}$ & $\mathrm{C}$ & Beneficial \\
\hline & $\begin{array}{l}\text { Topical erythromycin } \\
\text { or }\end{array}$ & B & Beneficial \\
\hline & $\begin{array}{l}\text { Topical clindamycin } \\
+\end{array}$ & B & Beneficial \\
\hline & Benzoyl peroxide & $\mathrm{C}$ & Beneficial \\
\hline \multirow[t]{5}{*}{ Moderate to severe } & $\begin{array}{l}\text { Oral erythromycin } \\
\text { or }\end{array}$ & $\mathrm{B}$ & Likely to be beneficial \\
\hline & $\begin{array}{l}\text { Oral cephalexin } \\
\quad+\end{array}$ & $\mathrm{B}$ & * \\
\hline & $\begin{array}{l}\text { Benzoyl peroxide } \\
\text { with or without }\end{array}$ & $\mathrm{C}$ & Beneficial \\
\hline & $\begin{array}{l}\text { Azelaic acid } \\
\text { or }\end{array}$ & B & Likely to be beneficial \\
\hline & Intralesional steroid injections & $\mathrm{C}$ & * \\
\hline \multirow[t]{4}{*}{ Fulminant } & $\begin{array}{l}\text { Oral erythromycin } \\
\quad+\end{array}$ & B & Likely to be beneficial \\
\hline & $\begin{array}{l}\text { Benzoyl peroxide } \\
\quad+\end{array}$ & $\mathrm{C}$ & Beneficial \\
\hline & $\begin{array}{l}\text { Azelaic acid } \\
\quad+\end{array}$ & B & Likely to be beneficial \\
\hline & Oral prednisone(short-term) & $\mathrm{C}$ & * \\
\hline
\end{tabular}

Data from Ref. 37.

*Evidence of a drug's benefit is not discussed in Ref. 37 . 
Table 3. Selected Topical Agents for Acne

\begin{tabular}{|c|c|c|c|c|}
\hline Agent & $\begin{array}{c}\text { FDA } \\
\text { Category }\end{array}$ & Mechanism of Action & Available Formulations & Notes \\
\hline Azelaic acid & $\mathrm{B}$ & $\begin{array}{l}\text { Antimicrobial } \\
\text { Comedolytic } \\
\text { Anti-inflammatory } \\
\text { Antityrosinase activity }\end{array}$ & $\begin{array}{l}\text { Cream (20\%; approved for acne) } \\
\text { Gel ( } 15 \% \text {; approved for rosacea) }\end{array}$ & $\begin{array}{l}\text { Monotherapy is possible } \\
\text { No known bacterial resistance } \\
\text { Can improve postinflammatory } \\
\text { hyperpigmentation }\end{array}$ \\
\hline Benzoyl peroxide & $\mathrm{C}$ & $\begin{array}{l}\text { Antibacterial } \\
\text { Comedolytic } \\
\text { Anti-inflammatory }\end{array}$ & $\begin{array}{l}\text { Wash, bar, pad, gel, mask, foam, } \\
\text { lotion, cream }(2.5-10 \%)\end{array}$ & $\begin{array}{l}\text { Monotherapy is possible } \\
\text { No known bacterial resistance } \\
\text { Can cause bleaching }\end{array}$ \\
\hline Salicylic acid & $\mathrm{C}$ & $\begin{array}{l}\text { Comedolytic } \\
\text { Keratolytic }\end{array}$ & $\begin{array}{l}\text { Lotion, cleanser, gel, cream, } \\
\text { foam, soap, toner, pads }(0.5- \\
6 \%)\end{array}$ & $\begin{array}{l}\text { Generally well-tolerated by patients } \\
\text { Less effective than azelaic acid or } \\
\text { benzoyl peroxide }\end{array}$ \\
\hline Erythromycin & B & Antibacterial & $\begin{array}{l}\text { Gel, solution, pad, ointment } \\
\quad(2 \%) \\
\text { Erythromycin/benzoyl peroxide } \\
\text { gel }(3 \% / 5 \%)\end{array}$ & $\begin{array}{l}\text { Should not to be used as } \\
\text { monotherapy } \\
\text { Bacterial resistance is diminished by } \\
\text { combining with benzoyl peroxide }\end{array}$ \\
\hline Clindamycin & B & Antibacterial & $\begin{array}{l}\text { Gel, lotion, solution, foam, swab } \\
\text { (1\%) } \\
\text { Clindamycin/benzoyl peroxide } \\
\text { gel }(1 \% / 5 \%, 1.2 \% / 2.5 \%)\end{array}$ & $\begin{array}{l}\text { Should not to be used as } \\
\text { monotherapy } \\
\text { Use with caution in patients with a } \\
\text { history of gastrointestinal disease } \\
\text { Bacterial resistance is diminished by } \\
\text { combining with benzoyl peroxide }\end{array}$ \\
\hline Tazarotene & $\mathrm{X}$ & $\begin{array}{l}\text { Comedolytic } \\
\text { Anti-inflammatory }\end{array}$ & Cream, gel, foam $(0.05 \% / 0.1 \%)$ & Contraindicated in pregnancy \\
\hline Tretinoin & $\mathrm{C}$ & $\begin{array}{l}\text { Comedolytic } \\
\text { Anti-inflammatory }\end{array}$ & $\begin{array}{l}\text { Gel }(0.01 \% / 0.025 \% / 0.05 \%), \\
\text { microsphere gel } \\
(0.04 \% / 0.08 \% / 0.1 \%), \text { cream } \\
(0.02-0.1 \%), \text { topical solution } \\
(0.05 \%)\end{array}$ & Not recommended in pregnancy \\
\hline Adapalene & $\mathrm{C}$ & $\begin{array}{l}\text { Comedolytic } \\
\text { Anti-inflammatory }\end{array}$ & $\begin{array}{l}\text { Lotion, cream }(0.1 \%) \\
\text { Gel }(0.1 \% / 0.3 \%) \\
\text { Adapalene/benzoyl peroxide gel } \\
\quad(0.1 \% / 2.5 \%)\end{array}$ & Not recommended in pregnancy \\
\hline Dapsone & $\mathrm{C}$ & $\begin{array}{l}\text { Anti-inflammatory } \\
\text { Antimicrobial }\end{array}$ & Gel $(5 \%)$ & $\begin{array}{l}\text { Low risk of maternal anemia, } \\
\text { neonatal hyperbilirubinemia, and } \\
\text { hemolytic anemia in patients } \\
\text { with G6PD deficiency (for } \\
\text { topical dapsone) }\end{array}$ \\
\hline
\end{tabular}

FDA, US Food and Drug Administration; G6PD, glucose-6-phospate dehydrogenase.

vulinic acid, photodynamic therapy, and FDA pregnancy. No date restrictions were applied. The search included meta-analyses, randomized controlled trials, clinical trials, and reviews. In addition, Clinical Evidence, EMBASE, the Cochrane database, and UpToDate were searched.

\section{Topical Treatments}

For mild to moderate acne, topical therapy is the standard of care. It is also an important component of the regimen for more severe acne and acts synergistically with oral agents. Quantifiable systemic absorption of topical anti-acne agents must be considered in pregnancy. Properties of commonly used topical agents are summarized in the following sections and in Table 3.

\section{Azelaic Acid}

Azelaic acid is classified as pregnancy category B because animal studies have shown no teratogenicity, but human data do not exist. Azelaic acid is a naturally occurring dicarboxylic acid with antimicrobial, comedolytic, and mild anti-inflammatory properties, with an added benefit of decreasing postinflammatory hyperpigmentation. There are no indications that Propionibacterium acnes may become resistant to azelaic acid. Following topical application, approximately $4 \%$ of the drug is absorbed systemically. ${ }^{5}$

\section{Benzoyl Peroxide}

Benzoyl peroxide is classified as pregnancy category C. Approximately $5 \%$ is absorbed systemically, and 
it is completely metabolized into benzoic acid, a food additive. ${ }^{6}$ Because of rapid renal clearance, no systemic toxicity is expected, and the risk of congenital malformations is theoretically small. ${ }^{5}$ Benzoyl peroxide is available as both prescription and nonprescription products in a variety of concentrations and vehicles. It has antimicrobial, comedolytic, and anti-inflammatory properties. To date, resistance of $P$. acnes to benzoyl peroxide has not been identified. ${ }^{5,7}$ Benzoyl peroxide is considered safe during pregnancy and helps to prevent the development of resistance when used in conjunction with antibiotics. ${ }^{3,6}$

\section{Salicylic Acid}

Salicylic acid is classified as pregnancy category C. There are no studies of topical salicylic acid use by humans during pregnancy, though malformations in rat embryos have resulted from systemic salicylic acid and aspirin administration during pregnancy. ${ }^{1}$ It is a keratolytic agent that is commonplace in over-the-counter acne remedies. Widespread application of high-concentration salicylic acid on hyperkeratotic skin has resulted in cases of salicylate toxicity, but there are no known cases associated with acne products. Risk during pregnancy is low if use is restricted to local areas for a limited duration. ${ }^{6}$

\section{Topical Antibiotics}

Topical antibiotics have long been used for the treatment of inflammatory acne; erythromycin and clindamycin are the 2 most commonly prescribed agents. Both are classified as pregnancy category B. Short-term use of topical erythromycin and clindamycin is safe during pregnancy. ${ }^{5}$ However, studies addressing the effects of chronic use are not available. ${ }^{1}$ Given the reported association of cases of Clostridium difficile diarrhea with topical clindamycin, it should be used with caution in patients with a history of gastrointestinal disease. ${ }^{8,9}$ Topical clindamycin and erythromycin reduce the amount of $P$. acnes in the sebaceous follicle by inhibiting bacterial protein synthesis and thereby suppressing inflammatory acne. Combining topical antibiotic therapy with topical benzoyl peroxide decreases the development of bacterial resistance and improves treatment efficacy. ${ }^{10,11}$

\section{Topical Retinoids}

Topical retinoids are vitamin A derivatives and have been used to treat acne for over 30 years. In the United States these agents include adapalene, tretinoin, and tazarotene. Adapalene and tretinoin are FDA pregnancy category $\mathrm{C}$ drugs, whereas tazarotene is a category $\mathrm{X}$ drug. These ratings partially stem from the commonly reported birth defects associated with the use of isotretinoin, a systemic retinoid. ${ }^{12}$ Thus, given its potential for high systemic concentrations with topical use, tazarotene should be avoided during pregnancy. ${ }^{5}$ Despite reports of possible birth defects, topical adapalene and tretinoin are unlikely to lead to congenital malformations given the small amount that is absorbed. ${ }^{13}$ A recent meta-analysis ruled out associated major increases in the rates of spontaneous abortions, congenital malformations, prematurity, and low birth weight. ${ }^{14}$ Mechanisms of action include modulation of keratinocyte differentiation, comedolysis, and anti-inflammation. Avoidance of these drugs is generally recommended in pregnant women because their risk-to-benefit ratio remains questionable.

\section{Topical Dapsone}

Topical dapsone is a synthetic sulfone with antimicrobial and anti-inflammatory properties. ${ }^{15}$ It is classified as pregnancy category C. High doses in animals have not shown teratogenic effects. ${ }^{16}$ To date, its use during pregnancy has not been associated with an increased risk of fetal malformations. ${ }^{17}$ Risk of maternal anemia, as well as hyperbilirubinemia and hemolytic anemia in neonates, is associated with oral dapsone in patients with glucose6-phosphate dehydrogenase deficiency, but the risk is low with topical dapsone. ${ }^{18}$ Topical dapsone was approved by the FDA in 2005 for the treatment of acne vulgaris. Caution should be exercised, given its relatively recent emergence on the market and the lack of controlled human studies evaluating its safety during pregnancy. It should be prescribed in pregnancy only when the benefits clearly outweigh the risks.

\section{Oral Treatments}

Some patients may not achieve satisfactory improvement using topical therapies alone. Oral therapies are primarily indicated for patients with moderate to severe inflammatory acne and in cases that 
Table 4. Selected Oral Antibiotics for Acne

\begin{tabular}{|c|c|c|c|}
\hline Agent & $\begin{array}{l}\text { FDA Pregnancy } \\
\text { Category }\end{array}$ & Dosage & Notes \\
\hline Erythromycin & B & $250-500 \mathrm{mg}, 2-4$ times/day & $\begin{array}{l}\text { Long-term use in pregnancy has not been } \\
\text { studied } \\
\text { Bacterial resistance is diminished by } \\
\text { combining with topical benzoyl peroxide } \\
\text { Hepatotoxicity is associated with } \\
\text { erythromycin estolate; not recommended for } \\
\text { pregnancy }\end{array}$ \\
\hline Azithromycin & B & $\begin{array}{l}\text { Dosing routine may vary, } \\
\text { eg, } 250 \mathrm{mg}, 3 \text { times/week }\end{array}$ & $\begin{array}{l}\text { Off-label indication } \\
\text { More flexible dosing regimen for less } \\
\text { compliant patients }\end{array}$ \\
\hline Cephalexin & B & $500 \mathrm{mg}$ twice daily & Concern for Staphylococcus resistance \\
\hline Amoxicillin & B & $250-500 \mathrm{mg}$ twice daily & $\begin{array}{l}\text { Use in early pregnancy may increase risk of oral } \\
\text { clefts }\end{array}$ \\
\hline Trimethoprim/sulfamethoxazole & $\mathrm{C}$ & $160 / 800 \mathrm{mg}$ twice per day & $\begin{array}{l}\text { Exposure during the first trimester is associated } \\
\text { with miscarriage }\end{array}$ \\
\hline Tetracycline & $\mathrm{D}$ & $250-500 \mathrm{mg}$ twice daily & $\begin{array}{l}\text { Toxic effects on fetal teeth and bone } \\
\text { Avoid in pregnancy }\end{array}$ \\
\hline Minocycline or doxycycline & $\mathrm{D}$ & $\begin{array}{l}50-100 \mathrm{mg} \\
\text { once or twice per day }\end{array}$ & $\begin{array}{l}\text { Toxic effects on fetal teeth and bone } \\
\text { Avoid in pregnancy }\end{array}$ \\
\hline
\end{tabular}

FDA, US Food and Drug Administration.

are recalcitrant to adequate trials of topical agents. Properties of commonly used oral therapies are outlined in the following sections as well as in Table 4.

\section{Oral Antibiotics}

Oral antibiotics improve inflammatory acne by inhibiting the growth of $P$. acnes in the pilosebaceous unit. Tetracycline antibiotics (including doxycycline and minocycline) also exert direct anti-inflammatory effects. The agents most commonly used by patients who are not pregnant include doxycycline, minocycline, erythromycin, azithromycin, cephalexin, and trimethoprim-sulfamethoxazole. Because of increasing bacterial resistance, it is generally recommended to (1) combine topical benzoyl peroxide with oral antibiotics, (2) limit the use of oral antibiotics to as short a duration as possible, and (3) avoid oral antibiotics for acne maintenance therapy. ${ }^{7,11}$ Switching between different oral antibiotics should also be avoided when possible to limit the development of bacterial resistance; if 1 oral antibiotic has proven effective in the past, it should be prescribed again. ${ }^{19}$ Oral antibiotics should be prescribed during pregnancy only when need has been clearly established.

Erythromycin is a macrolide in pregnancy category B. Single doses of the drug cross the placenta poorly, resulting in low concentrations in fetal tis- sue. Erythromycin is generally considered safe during any stage of pregnancy when administered for a few weeks. ${ }^{20}$ It may be considered the antibiotic of choice for treatment of severe inflammatory acne in pregnant women. However, long-term use of the drug ( $>6$ weeks) has not been studied. Notably, erythromycin estolate is contraindicated because of drug-related maternal hepatotoxicity. ${ }^{21}$

Azithromycin is another macrolide that is classified in FDA pregnancy category B. Animal studies have shown that azithromycin crosses the placenta without causing negative effects to the fetus. ${ }^{22}$ Azithromycin is considered compatible with pregnant patients with acne but has less available safety data than erythromycin. ${ }^{6}$

Amoxicillin belongs to the aminopenicillin class of antibiotics and is classified as FDA pregnancy category B. Its use in early pregnancy may increase the risk of oral clefts. ${ }^{23}$ Amoxicillin can be used alone or in combination with other agents as an option for treatment-resistant acne. ${ }^{24}$ It is associated with gastrointestinal side effects such as nausea and vomiting. ${ }^{3}$

Cephalexin is a first-generation cephalosporin with anti-inflammatory properties and is considered a pregnancy category B drug. Cephalexin has not been associated with fetal defects in animal studies, with inadequate controlled data from human subjects. While effective as an anti-acne agent, 
there is some concern about the development of resistance against Staphylococcus. ${ }^{25}$

Trimethoprim acts as a folate antagonist and is classified as a pregnancy category $\mathrm{C}$ drug. A recent study showed that trimethoprim exposure during the first trimester was associated with a doubled risk of miscarriage. ${ }^{26}$ Therefore the use of trimethoprim-sulfamethoxazole is recommended for use in pregnancy only when there are no alternatives and when the benefits outweigh the risks.

Tetracyclines are classified under pregnancy category D. Animal studies have revealed evidence of embryo toxicity and fetotoxicity, including toxic effects on fetal teeth and bone. Tetracycline antibiotics bind to calcium orthophosphate and are therefore actively deposited in teeth and bones. In teeth the deposition of the drug is permanent, causing the deciduous teeth of children exposed to the medication after the 20th week of gestation to become yellow, darkening with time. ${ }^{22}$ Deposition in bones has been suggested to result in a reversible decrease in fetal size and to inhibit fibula growth, especially with chronic use of the medication. Tetracyclines should be avoided during pregnancy, especially after the first trimester.

It is important to note that additional evidence is needed regarding the recommended durations of these therapies. The effects of chronic usage of these antibiotics on the fetus are not known. This consideration must be weighed against the severity of acne and alternative topical therapies. Use of systemic antibiotics should be restricted to the second and third trimesters, after the completion of organogenesis, with duration of therapy limited to 4 to 6 weeks.

\section{Oral Corticosteroids}

Severe acne that is resistant to antibiotic therapy may benefit from the use of oral corticosteroids. Prednisone belongs to FDA pregnancy category C. The drug has been associated with cleft palate, decreased brain growth, reduced myelination, and smaller head circumference among animals. ${ }^{27,28}$ Human studies showed an increased risk of oral cleft and a slight increase in miscarriage rates and preterm births. ${ }^{27,29} \mathrm{Few}$ data are available on the transfer of intralesional or topical steroids across the placenta, although it has been shown that topical steroids can be absorbed systemically. ${ }^{28}$ Prednisone may be used for severe or fulminant acne cases after the first trimester. Conservative use of steroids, such as small amounts of intralesional steroids and short courses of oral steroids required for rare, fulminant cases of acne vulgaris, is unlikely to pose additional risks to the fetus. Prednisone dosage should be limited to $<20 \mathrm{mg} / \mathrm{day}^{6}$ over a course of no more than 1 month during the third trimester.

\section{Oral Retinoids}

Isotretinoin is often prescribed to nonpregnant patients with recalcitrant, nodulocystic acne vulgaris. The teratogenic effects of isotretinoin are well known, and the drug is classified as FDA pregnancy category $\mathrm{X}$. The medication leads to characteristic malformations involving the craniofacial area, central nervous system, cardiovascular system, thymus, and parathyroid glands. Isotretinoin was approved in 1982 and works by reducing sebum production and normalizing keratinization. ${ }^{12}$ Isotretinoin is absolutely contraindicated during pregnancy.

\section{Zinc}

Zinc provides another option for pregnant patients with acne. Zinc sulfate is considered a FDA pregnancy category $\mathrm{C}$ drug, whereas zinc gluconate has not been formally categorized. Animal studies and human studies including pregnant women treated for acne have not revealed increased risks of fetal abnormalities, and the risk of fetal harm at doses $<75 \mathrm{mg}$ /day is remote. ${ }^{30}$ Zinc has antibacterial, anti-inflammatory, and antisebum properties, and has been found to be effective against mild to moderate inflammatory acne when used alone or in combination with other anti-acne agents. ${ }^{17,31,32}$ The recommended dietary allowance for zinc during pregnancy is $11 \mathrm{mg} /$ day. Potential side effects include nausea and vomiting, usually on a dosedependent and transient basis. ${ }^{17}$

\section{Procedure-Based Treatment}

Pregnant patients and their providers may also choose procedure-based options as alternatives or adjuncts to the topical and oral agents discussed above with regard to management of acne. Issues of cost and shortage of available data are issues to be considered for these options.

\section{Glycolic Acid}

Glycolic acid is a pregnancy category $\mathrm{N}$ drug - that is, it is not rated-and is used topically for acne 


\begin{tabular}{|c|c|c|}
\hline Clinical Recommendation & $\begin{array}{l}\text { Evidence } \\
\text { Rating* }\end{array}$ & References \\
\hline Topical azelaic acid $(15 \%$ or $20 \%)$ and benzoyl peroxide $(2.5-5 \%)$ are effective baseline agents. & $\mathrm{B}$ & 36,37 \\
\hline $\begin{array}{l}\text { Topical erythromycin in combination with benzoyl peroxide ( } 5 \% \text { maximum) can be used as alternative } \\
\text { treatment for inflammatory acne. }\end{array}$ & $\mathrm{C}$ & 36 \\
\hline $\begin{array}{l}\text { Topical clindamycin in combination with benzoyl peroxide can be used as alternative treatment for } \\
\text { inflammatory acne. }\end{array}$ & $\mathrm{C}$ & 37 \\
\hline $\begin{array}{l}\text { Topical dapsone is a newer anti-acne agent with less available safety data and should be used with } \\
\text { caution in pregnant patients. }\end{array}$ & $\mathrm{C}$ & 18 \\
\hline $\begin{array}{l}\text { Topical and oral antibiotics (eg, erythromycin) should be used in combination with benzoyl peroxide } \\
\text { to reduce the risk of bacterial resistance. }\end{array}$ & $\mathrm{C}$ & 11 \\
\hline Oral cephalexin can be used in moderate to severe inflammatory acne. & $\mathrm{C}$ & 25 \\
\hline Intralesional steroid injections can be used to treat moderate to severe inflammatory acne. & $\mathrm{C}$ & 33 \\
\hline Oral glucocorticoids can be used short term to treat fulminant acne after the first trimester. & $\mathrm{C}$ & 36 \\
\hline
\end{tabular}

${ }^{*} \mathrm{~B}=$ inconsistent or limited-quality patient-oriented evidence; $\mathrm{C}=$ consensus, disease-oriented evidence, usual practice, expert opinion, or case series. For information about the Strength of Recommendation Taxonomy evidence rating system, go to http:// www.aafp.org/afpsort.xml.

management. No published reports demonstrate any adverse effects during pregnancy. Glycolic acid peels can lead to subcorneal epidermolysis, thus eliminating the follicular obstruction seen with this condition. Studies have shown improvement in both inflammatory and comedonal acne, although closed comedones may be slower to respond. It also has the added benefits of improving postinflammatory changes and increasing the cutaneous absorption of topical agents. ${ }^{33}$

\section{Photodynamic Therapy}

Photodynamic therapy provides another option for pregnant patients. The photosensitizing agent aminolevulinic acid is classified as pregnancy category C. Animal reproductive studies are not available. Compared with control treatment, photodynamic therapy resulted in a statistically significant improvement in acne severity, along with sustained results for up to 20 weeks after multiple treatments. ${ }^{34,35}$ The lack of insurance coverage and the frequency of required sessions at a dermatologist's office may present barriers to use. ${ }^{33}$

\section{Summary of Recommendations}

In this review we outlined numerous options for providers who treat pregnant patients with acne. We provide the following simplified approach as a starting point for busy providers when dealing with pregnant patients. For mild acne characterized primarily by noninflammatory lesions, topical azelaic acid or benzoyl peroxide can be recommended as baseline therapy. For acne involving inflammatory

Table 6. Costs of Agents

\begin{tabular}{|c|c|c|c|c|c|}
\hline \multicolumn{2}{|l|}{ Topical Treatments } & \multicolumn{2}{|c|}{ Oral Treatments } & \multicolumn{2}{|l|}{ Procedures } \\
\hline Agent & Cost & Agent & Cost & Agent & Cost \\
\hline Benzoyl peroxide & $\$$ & Azithromycin & $\$$ & Glycolic acid peel & $\$ \$ \$$ \\
\hline Salicylic acid & $\$$ & Amoxicillin & $\$$ & Photodynamic therapy & $\$ \$ \$$ \\
\hline Topical erythromycin & $\$$ & Cephalexin & $\$$ & & \\
\hline Topical clindamycin & $\$$ & Prednisone & $\$$ & & \\
\hline Benzamycin (erythromycin/benzoyl peroxide) & $\$ \$$ & Zinc & $\$$ & & \\
\hline Benzaclin (clindamycin/benzoyl peroxide) & $\$ \$$ & Erythromycin & $\$ \$$ & & \\
\hline Azelaic acid & $\$ \$ \$$ & & & & \\
\hline Topical dapsone & $\$ \$ \$$ & & & & \\
\hline
\end{tabular}

Estimated costs (actual costs may vary depending on insurance plans, pharmacy, location, and other variables): $\$=\$ 0-\$ 50 ; \$ \$=$ $\$ 50-\$ 150 ; \$ \$ \$=\geq \$ 150$. 
lesions, starting with a combination of topical erythromycin or clindamycin with benzoyl peroxide is recommended. Moderate to severe inflammatory acne can be managed with oral erythromycin or cephalexin, which are safe when used for only a few weeks. A course of oral prednisolone no longer than a month may be useful for treating fulminant nodular cystic acne after the first trimester. In general, topical and oral antibiotics should not be used as monotherapy, but should be combined with topical benzoyl peroxide to decrease bacterial resistance. Additional options discussed in this review should be considered based on patient response and preference. Key recommendations are provided in Table 5, and relevant cost information is provided in Table 6. We hope providers may find this review helpful in navigating the challenges of managing acne in pregnant patients.

\section{References}

1. Akhavan A, Bershad S. Topical acne drugs: review of clinical properties, systemic exposure, and safety. Am J Clin Dermatol 2003;4:473-92.

2. Jones SV, Ambros-Rudolph C, Nelson-Piercy C. Skin disease in pregnancy. BMJ 2014;348:g3489.

3. Pugashetti R, Shinkai K. Treatment of acne vulgaris in pregnant patients. Dermatol Ther 2013;26:30211.

4. Dréno B, Blouin E, Moyse D, Bodokh I, Knol A, Khammari A. Acne in pregnant women: a French survey. Acta Derm Venereol 2014;94:82-3.

5. Wolverton SE, ed. Comprehensive dermatologic drug therapy. 3rd ed. Philadelphia: Saunders; 2012.

6. Murase JE, Heller MM, Butler DC. Safety of dermatologic medications in pregnancy and lactation: part I. Pregnancy. J Am Acad Dermatol 2014;70: 401.e1-14; quiz 415.

7. Williams HC, Dellavalle RP, Garner S. Acne vulgaris. Lancet 2012;379:361-72.

8. Parry MF, Rha CK. Pseudomembranous colitis caused by topical clindamycin phosphate. Arch Dermatol 1986;122:583-4.

9. Siegle RJ, Fekety R, Sarbone PD, Finch RN, Deery HG, Voorhees JJ. Effects of topical clindamycin on intestinal microflora in patients with acne. J Am Acad Dermatol 1986;15(2 Pt 1):180-5.

10. Patel M, Bowe WP, Heughebaert C, Shalita AR. The development of antimicrobial resistance due to the antibiotic treatment of acne vulgaris: a review. J Drugs Dermatol 2010;9:655-64.

11. Kinney MA, Yentzer BA, Fleischer AB, Feldman SR. Trends in the treatment of acne vulgaris: are measures being taken to avoid antimicrobial resistance? J Drugs Dermatol 2010;9:519-24.
12. Berard A, Azoulay L, Koren G, Blais L, Perreault S, Oraichi D. Isotretinoin, pregnancies, abortions and birth defects: a population-based perspective. $\mathrm{Br} \mathrm{J}$ Clin Pharmacol 2007;63:196-205.

13. Panchaud A, Csajka C, Merlob P. Pregnancy outcome following exposure to topical retinoids: prospective study. J Clin Pharmacol 2012;52:1844-51.

14. Kaplan YC, Ozsarfati J, Etwel F, Nickel C, Nulman I, Koren G. Pregnancy outcomes following first trimester exposure to topical retinoids : a systematic review and meta-analysis. Br J Dermatol 2015;173: 1132-41.

15. Gamble R, Dunn J, Dawson A, et al. Topical antimicrobial treatment of acne vulgaris: an evidencebased review. Am J Clin Dermatol 2012;13:141-52.

16. Nosten F, McGready R, d'Alessandro U, et al. Antimalarial drugs in pregnancy: a review. Curr Drug Saf 2006;1:1-15.

17. James KA, Burkhart CN, Morrell DS. Emerging drugs for acne. Expert Opin Emerg Drugs 2009;14: $649-59$.

18. Kong YL, Tey HL. Treatment of acne vulgaris during pregnancy and lactation. Drugs 2013;73:779-87.

19. Thiboutot D, Gollnick H, Bettoli V, et al. New insights into the management of acne: an update from the Global Alliance to Improve Outcomes in Acne Group. J Am Acad Dermatol 2009;60(5 Suppl): S1-50.

20. Romoren M, Lindbaek M, Nordeng H. Pregnancy outcome after gestational exposure to erythromycin-a population-based register study from Norway. Br J Clin Pharmacol 2012;74:1053-62.

21. Al Hammadi A, Al-Haddab M, Sasseville D. Dermatologic treatment during pregnancy: practical overview. J Cutan Med Surg 2006;10:183-92.

22. Hale EK, Pomeranz MK. Dermatologic agents during pregnancy and lactation: an update and clinical review. Int J Dermatol 2002;41:197-203.

23. Lin KJ, Mitchell AA, Yau W-P, Louik C, Hernández-Díaz S. Maternal exposure to amoxicillin and the risk of oral clefts. Epidemiology 2012;23:699-705.

24. Turowski CB, James WD. The efficacy and safety of amoxicillin, trimethoprim-sulfamethoxazole, and spironolactone for treatment-resistant acne vulgaris. Adv Dermatol 2007;23:155-63.

25. Fenner JA, Wiss K, Levin NA. Oral cephalexin for acne vulgaris: clinical experience with 93 patients. Pediatr Dermatol 2008;25:179-83.

26. Andersen JT, Petersen M, Jimenez-Solem E, et al. Trimethoprim use in early pregnancy and the risk of miscarriage: a register-based nationwide cohort study. Epidemiol Infect 2013;141:1749-55.

27. Park-Wyllie L, Mazzotta P, Pastuszak A, et al. Birth defects after maternal exposure to corticosteroids: prospective cohort study and meta-analysis of epidemiological studies. Teratology 2000;62:385-92. 
28. Rennick GJ. Use of systemic glucocorticosteroids in pregnancy: be alert but not alarmed. Australas J Dermatol 2006;47:34-6.

29. Gur C, Diav-Citrin O, Shechtman S, Arnon J, Ornoy A. Pregnancy outcome after first trimester exposure to corticosteroids: a prospective controlled study. Reprod Toxicol 2004;18:93-101.

30. Dréno B, Blouin E. [Acne, pregnant women and zinc salts: a literature review]. Ann Dermatol Venereol 2008;135:27-33.

31. Brocard A, Dréno B. Innate immunity: a crucial target for zinc in the treatment of inflammatory dermatosis. J Eur Acad Dermatol Venereol 2011;25: 1146-52.

32. Brandt S. The clinical effects of zinc as a topical or oral agent on the clinical response and pathophysiologic mechanisms of acne: a systematic review of the literature. J Drugs Dermatol 2013;12:542-5.
33. Taub AF. Procedural treatments for acne vulgaris. Dermatol Surg 2007;33:1005-26.

34. Hongcharu W, Taylor CR, Chang Y, Aghassi D, Suthamjariya K, Anderson RR. Topical ALA-photodynamic therapy for the treatment of acne vulgaris. J Invest Dermatol 2000;115:183-92.

35. de Leeuw J, van der Beek N, Bjerring P, Neumann HAM. Photodynamic therapy of acne vulgaris using 5 -aminolevulinic acid $0.5 \%$ liposomal spray and intense pulsed light in combination with topical keratolytic agents. J Eur Acad Dermatol Venereol 2010; 24:460-9.

36. Dréno B, Layton A, Zouboulis CC, et al. Adult female acne: a new paradigm. J Eur Acad Dermatol Venereol 2013;27:1063-70.

37. Purdy S, de Berker D. Acne vulgaris. BMJ Clin Evid 2011;2011. pii. 1714 . 